\title{
Genetics and expression of anthocyanin pathway genes in the major skin- pigmented Portuguese cultivar 'Vinhão' developing berries
}

\author{
Vanessa Ferreira $^{\mathrm{a}, \mathrm{b}, *}$, Isaura Castro ${ }^{\mathrm{a}}$, David Carrasco ${ }^{\mathrm{b}}$, Olinda Pinto-Carnide ${ }^{\mathrm{a}}$, \\ Rosa Arroyo-García ${ }^{\mathrm{b}}$

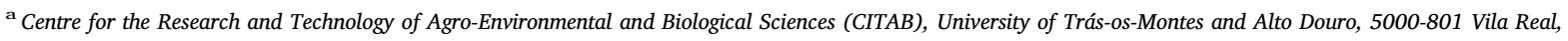 \\ Portugal \\ ${ }^{\mathrm{b}}$ Centre for Plant Biotechnology and Genomics (UPM-INIA, CBGP), Campus de Montegancedo, Autovía M40 km. 38, 28223 Pozuelo de Alarcón, Madrid, Spain
}

\section{A R T I C L E I N F O}

\section{Keywords:}

Vinhão

Berry skin color

$M Y B A 1 / A 2$

Gene expression

\begin{abstract}
A B S T R A C T
'Vinhão' is an autochthonous Portuguese cultivar with an intense black-bluish skin color, highly appreciated due to this feature. This study aimed to give the first insights into the genetic background that may be responsible for the skin color properties of cv. 'Vinhão'. For this purpose, the allelic composition of MYBA1 and MYBA2 genes was investigated, along with quantification of the expression levels of structural and regulatory genes involved in the anthocyanin biosynthetic pathway via qRT-PCR. The molecular characterization of MYBA1 and MYBA2 loci revealed that cv. 'Vinhão' is homozygous for the functional allele in both genes, corresponding to the most ancestral haplotype, which is consistent with the high colored phenotype that characterizes this cultivar. There were no differences in the DNA sequence of the MYBA1 promoter region between cv. 'Vinhão' and the grapevine reference genome Pinot Noir. The expression patterns of genes playing key functional roles in anthocyanin biosynthesis was analyzed in four developmental stages. The dynamics occurring throughout grape berry development revealed the involvement of these genes in the progression of key development events, mainly from veraison to mature berries. These findings provide the first molecular characterization focused on the skin color feature of cv. 'Vinhão' to improve our understanding of the genetics behind its intense skin pigmentation.
\end{abstract}

\section{Introduction}

'Vinhão' is a high quality autochthonous cultivar and represents the most used cultivar in Vinhos Verdes and Lafões Portuguese DOC regions for red wine production. In Portugal, it is also known as Sousão in Douro DOC region, which corresponds to the main national synonym for this red cultivar. In Spain, cv. 'Vinhão' is cultivated in Galicia region under the name 'Sousón' (Castro et al., 2012, 2011; Martín et al., 2006). As reported by Fonseca (1791), the possible expansion of cv. 'Vinhão' through the provinces of Minho and Douro in Portugal and Galicia in Spain, could have occured during the middle of the 19th century by Galician people that worked in Douro viticulture due to the demand for workers generated by the increasing exportation of Porto wine to England. Although this red cultivar has been neglected either by producers or by the wine consumers in the past, nowadays, has gain some expression in the current market mainly due its color properties (intense black-bluish skin color), which are highly appreciated once adds intense color to the wines.
In grapevine, the berry color is mostly determined by the presence or absence of anthocyanins, usually in the epidermal and hypodermal layers of the berry, being colorless in the flesh. However, anthocyanin synthesis is also activated in the flesh of some grapevine cultivars, which are called teinturier (dyer) cultivars (Falginella et al., 2012), such as cv. 'Alicante Bouschet'. Anthocyanin synthesis starts during veraison and is part of the flavonoid pathway that also produces flavonols, catechins, and proanthocyanidins through specific enzymes that use the same metabolic intermediates.

The main anthocyanidins synthesized in grapes are cyanidin and peonidin (di-substituted in the lateral B-ring) and delphinidin, petunidin and malvidin (tri-substituted), which are synthesized via different branches of the pathway. The flavonoid $3^{\prime}, 5^{\prime}$-hydroxylase $\left(\mathrm{F}^{\prime} 5^{\prime} \mathrm{H}\right)$ enzymes compete for substrates with the similar enzyme flavonoid $3^{\prime}$ hydroxylase $\left(\mathrm{F}^{\prime} \mathrm{H}\right)$. If $\mathrm{F} 3^{\prime} 5^{\prime} \mathrm{H}$ activity prevails over $\mathrm{F} 3^{\prime} \mathrm{H}$, the products of flavonoid hydroxylases are predominately driven into the branch of the pathway that leads to the synthesis of delphinidin (blue purple derivatives) at the expense of those channeled into the synthesis of

\footnotetext{
* Corresponding author at: Centre for the Research and Technology of Agro-Environmental and Biological Sciences (CITAB), University of Trás-os-Montes and Alto Douro, 5000-801 Vila Real, Portugal.

E-mail address: vanessa.cm.ferreira29@gmail.com (V. Ferreira).
} 
cyanidin (red derivatives) (De Lorenzis et al., 2016; Falginella et al., 2012).

Extensive molecular studies have been focused on grape color variation through the analysis of several genes of the anthocyanin biosynthetic pathway, including transcription factors with regulatory function on structural genes of the pathway. Among the structural genes, $V$. vinifera UDP-glucose:flavonoid 3-O-glucosyltransferase $(V v U F G T)$ revealed to be a master switch in the control of berry color, strictly regulated by two very similar adjacent transcription factors, MYBA1 and MYBA2 (Ageorges et al., 2006; Kobayashi et al., 2004; Lijavetzky et al., 2006; This et al., 2007; Walker et al., 2007). These genes are inherited together and are often considered as part of a single large locus called by 'berry color locus' (Carrasco et al., 2015). The occurrence of different mutations that leads to the disruption of these two genes conducted to several different phenotypes, namely to the unpigmented phenotype of most white-skinned cultivars, but also other color shades of grey, pink, red or black. MYBA1 gene inactivation occurs through the insertion of the Gret1 retrotransposon in its promotor region and different alleles have been described: VvmybA1a (nonfunctional allele) containing the complete Gret1 retrotransposon inserted upstream of the MYBA1 coding sequence; $V v m y b A 1 b$ (functional allele) harboring a single copy of the Gret1 $3^{\prime}$-LTR region (solo $3^{\prime}$-LTR) in the $5^{\prime}$-flanking region near the coding sequences of MYBA1 as a consequence of the retrotransposon partial excision, which allows the gene expression; VvmybA1c that completely lacks the Gret1 retrotransposon insertion is considered the wild-type functional allele, prior to the insertion of Gret1; VvmybA1d, the null allele, which arises from the complete deletion of the MYBA1 gene region (Azuma et al., 2007; Kobayashi et al., 2004; Yakushiji et al., 2006). MYBA2 gene is inactivated by two non-conservative mutations: i) SNP at position VvMYBA2R44 (or K980) in the coding sequence ( $T$ instead of G) that leads to an amino acid substitution (change of arginine at in the red allele to leucine in the white allele), rendering non-function; ii) frame shift resulting in a smaller protein (dinucleotide deletion altering the reading frame at the amino acid position 258) (Walker et al., 2007). Moreover, the altered pigmentation of berries' skin can be affected by different mutation patterns on the skin cell layers of the shoot apical meristem (Ferreira et al., 2018; Migliaro et al., 2017; Vezzulli et al., 2012).

'Vinhão' is a well-defined cultivar from the ampelographic and chemical point of view, with a clearly visible accumulation of anthocyanins in its berry skin, which significantly affect wine quality (Dopico-García et al., 2008; Teixeira et al., 2016). However, the molecular causes of the berry skin color trait on cv. 'Vinhão', with an extraordinary capacity to extract color to must, dying like no other Portuguese cultivar, have never been investigated before. The present work aims to characterize cv. 'Vinhão' at different genetic levels related with berry skin color: MYBA1 and MYBA2 genes polymorphisms and transcriptional regulation during berry development of genes involved in the anthocyanin biosynthetic pathway, intending to add more value to this extremely pigmented cultivar both from a historical and a scientific point of view.

\section{Material and methods}

\subsection{Berry sampling}

Grapevine berries of Vitis vinifera L. cv. 'Vinhão' (clone VN0249) were sampled in a grapevine germplasm collection from North of Portugal at 2015, the ampelographic collection of the "Vinhos Verdes Region Viticulture Comission' (CVRVV) 'Estação Vitivinícola Amândio Galhano' in Arcos de Valdevez ( $\left.41^{\circ} 81^{\prime} \mathrm{N}, 8^{\circ} 41^{\prime} \mathrm{W}\right)$, inside 'Vinhos Verdes' DOC Region. Three replications were collected during fruit development, in four sampling dates, corresponding to the following developmental stages: green soft (berries beginning to touch), veraison (berries changes color), advanced ripening berries and full maturation (berries ripe for harvest). Each replication contained at least 15 berries randomly picked from 10 vines. Berries were immediately frozen in liquid nitrogen in the vineyard and then stored at $-80^{\circ} \mathrm{C}$ until being processed.

\subsection{Varietal identity through microsatellite analysis}

Genomic DNA was isolated from young leaves using a DNeasy Plant Mini Kit (Qiagen, Valencia, CA, USA) according to the manufacturer's protocol. Twelve nuclear microsatellite markers were studied using two multiplex PCRs involving VVS2, VVMD5 andVVMD7 for set A, and VVMD27, ssrVrZAG62 and ssrVrZAG79 for set B. The remaining six microsatellites were amplified by individual PCR (VVMD28, VVMD32, VVIv37, VVIv67, VVIp31 and VMC4f3), according to the method of Castro et al. (2011).

\subsection{PCR analysis of MYBA1 gene structure and sequencing}

Two PCR assays were used in order to determine the presence or absence of the Gret1 retrotransposon in the MYBA1 promoter region. The presence of Gret1 retrotransposon in the MYBA1 promoter region (VvmybA1a allele, non-functional) was detected using the primers F1 (5'- AAAAAGGGGGGCAATGTAGGGACCC- $3^{\prime}$ ) and d3 (5'-CCTGCAG CTTTTTCGGCATCT- $3^{\prime}$ ) and PCR amplifications were performed as reported in Lijavetzky et al. (2006). PCR reactions to amplify putative functional alleles were assessed with FD2 (5'- TAGCTGCTGCCACTGC ATAG- $3^{\prime}$ ) and R1 (5'-GAACCTCCTTTTTGAAGTGGTGACT- 3') primers, as recommended by Azuma et al. (2008). PCR fragments were separated by electrophoresis in $1.5 \%(\mathrm{w} / \mathrm{v})$ agarose gel in TBE buffer, stained with ethidium bromide and photographed under UV light.

PCR amplification to isolate MYBA1 promotor region and part of the coding sequence was performed using the FD2 and R1 primers as described above. PCR fragments were separated as previously described and purified using the NucleoSpin Gel and PCR Clean-up (MachereyNagel - Fischer Scientific, Düren, Germany). PCR amplicons resulting from amplification were directly sequenced at STABVIDA company (http://www.stabvida.com). Sequence analysis and alignment were performed using the SnapGene ${ }^{\circledast}$ software v.2.7.3 (GSL Biotech, Chicago, IL, USA; http://snapgene.com). The alignments of reverse and forward sequences were applied to produce consensus sequences. The amplicon sequences were searched by BLAST-N against the genome assembly.

\subsection{MYBA2 polymorphism through SNaPshot assay}

For MYBA2 gene, the single nucleotide polymorphism (SNP), VvMYBA2R44 (K980) was investigated by a SNaPshot assay, according to the protocol reported in the ABI PRISM SNaPshot Multiplex kit (Life Technology Corporation, Foster City, CA, USA). PCR fragments were separated by electrophoresis in $0.8 \%(\mathrm{w} / \mathrm{v})$ agarose gel in TBE buffer, stained with ethidium bromide, and purified by QIAquick Gel Extraction Kit (QIAGEN, Düren, Germany) according to the manufacturer's instructions. The SNaPshot PCR products were enzymatically treated with $1 \mathrm{U}$ each of calf intestinal alkaline phosphatase (CIP; New England Biolabs, Beverly, MA, USA) to degrade excess PCR primers and dNTPs and incubated at $37^{\circ} \mathrm{C}$ for $1 \mathrm{~h}$, followed by $15 \mathrm{~min}$ at $75^{\circ} \mathrm{C}$ to inactivate the enzyme. The purified SNaPshot PCR products were detected on capillary electrophoresis instrument ABI PRISM 310 Genetic Analyzer (PE Applied Biosystems, Foster City, CA, USA) at the Genomics Unit of the Madrid Science Park (fpcm.es/en/servicios-cientificos) and data analysis was performed by Peak ScannerTM Software v1.0 (Applied Biosystems, Foster City, CA, USA).

\subsection{RNA isolation and complementary DNA synthesis}

For gene expression studies, total RNA was extracted from berry skins according to the procedures described by Reid et al. (2006). 
Briefly, $1 \mathrm{~mL}$ of pre-warmed $\left(65^{\circ} \mathrm{C}\right)$ extraction buffer $[300 \mathrm{mM}$ Tris $\mathrm{HCl}$ (pH 8), 25 mM EDTA, $2 \mathrm{M} \mathrm{NaCl}, 2 \%$ CTAB, 2\% PVP, 0.05\% spermidine trihydrochloride] and $1 \mathrm{~mL}$ of $\beta$-mercaptoethanol were added to the ground powder tissue. Samples were incubated at $65^{\circ} \mathrm{C}$ for $10 \mathrm{~min}$ and then extracted twice with chloroform-isoamyl alcohol (24:1), with a centrifugation at $30.000 \times g$ for $20 \mathrm{~min}$ at $4{ }^{\circ} \mathrm{C}$. To the supernatant, 0.1 v $3 \mathrm{M} \mathrm{NaOAc}(\mathrm{pH} 5.2$ ) and $0.6 \mathrm{v}$ isopropanol were added, mixed, and then stored at $-80^{\circ} \mathrm{C}$ for $30 \mathrm{~min}$. Nucleic acid pellets were collected by centrifugation at $3.500 \times g$ for $30 \mathrm{~min}$ at $4{ }^{\circ} \mathrm{C}$ and then dissolved in $0.5 \mathrm{~mL}$ Tris-EDTA ( $\mathrm{pH}$ 8). To selectively precipitate the RNA, $125 \mu \mathrm{L}$ of $10 \mathrm{M} \mathrm{LiCl}$ was added and the samples were stored overnight at $4{ }^{\circ} \mathrm{C}$. The precipitated RNA was pelleted in the following day by centrifugation, washed with $4{ }^{\circ} \mathrm{C} 70 \% \mathrm{EtOH}$, air dried and dissolved in $40 \mu \mathrm{L}$ of DEPCtreated water. Total RNA was further purified using the E.Z.N.A. ${ }^{\circ}$ MicroElute RNA Clean Up Kit (Omega Bio-Tek, Norcross, GA, USA) following the standard protocol. RNA concentration and $260 / 280 \mathrm{~nm}$ ratios were determined before and after DNase I digestion with a NanoDrop ND-1000 spectrophotometer (NanoDrop Technologies, Wilmington, DE, USA). Total RNA (200 ng) was reverse transcribed with the $\mathrm{qScript}^{\mathrm{TM}}$ cDNA SuperMix (Quanta BioSciences, Gaithersburg, MD, USA) according to the supplied protocol.

\subsection{Quantitative reverse transcription PCR ( $q R T-P C R$ ) expression analysis}

The differential transcript level of genes involved in the biosynthesis of anthocyanins (CHS1, CHS3, F3'H1a, F3'5'H1a, F3'5'Hj, DFR, FLS4, ANR, LAR1, LAR2, LDOX, UFGT and OMTC) and transcription factors related with this pathway (MYBA1, MYBA2, MYB4b, MYB5a and $M Y B 5 b$ ) was determined by qRT-PCR using a 7300 Real Time PCR System (Applied Biosystems, Foster City, CA, USA). Genes selection was performed based on the previously described expression levels of these genes analyzed on different grapevine cultivars during berry development (Ali et al., 2011; De Lorenzis et al., 2016; Falginella et al., 2012)

Each PCR reaction $(20 \mu \mathrm{L})$ contained $200 \mathrm{mM}$ of each primer, $3 \mu \mathrm{L}$ of cDNA (1:30 dilution of the synthesis reaction), 1 x SYBR Green RealTime PCR Master Mix (Thermo Fisher Scientific, Waltham, MA, USA) and water up to $20 \mu \mathrm{L}$. Thermal cycling conditions were $95^{\circ} \mathrm{C}$ for $10 \mathrm{~min}$, followed by 40 cycles of $95^{\circ} \mathrm{C}$ for $15 \mathrm{~s}$, annealing (variable temperatures) for $30 \mathrm{~s}$ and $72{ }^{\circ} \mathrm{C}$ for $30 \mathrm{~s} \mathrm{~A}$ melting cycle with temperature ranging from 60 to $95^{\circ} \mathrm{C}$ was included in order to detect nonspecific amplification in cDNA samples. Each one of the three biological replicates used to extract RNA and synthetize cDNA were used for qRTPCR reaction in duplicate. Gene transcripts were quantified upon normalization to Elongation factor 1-alpha $(E F 1 \alpha)$ by comparing the threshold cycle (Ct) of each target gene with geometric mean of EF1 $\alpha$ Ct. The relative quantification per each gene was calculated by the $2^{-\Delta \mathrm{Ct}}$ method, where $\Delta \mathrm{Ct}$ is the difference in threshold cycle between the geometric means of the target gene and the reference gene.

\section{Results and discussion}

A genotypic description of twelve SSR loci was used to ascertain the genetic identity of the highly pigmented cv. 'Vinhão' (Fig. 1a-b). Among the set of microsatellites analyzed, the OIV core set VVS2, VVMD5, VVMD7, VVMD27, ssrVrZAG62 and ssrVrZAG79 that correspond to OIV801 to OIV806 descriptors (OIV, 2009), established by the European Project GENRES \# 81 for the identification of grapevine cultivars, was included along with six other SSR loci VVMD28, VVMD32, VVIv37, VVIv67, VVIp31 and VMC4f3 to perform a more accurate grape cultivar authentication. The genetic identity of cv. 'Vinhão' was ascertained by comparison with fingerprinting data previously reported by Castro et al. (2011) (Fig. 1b). It was also concluded that cv. 'Vinhão' share a high number of alleles with the red cultivar 'Amaral', another autochthonous cultivar from Vinhos Verdes DOC region that is described as an ancient cultivar, with an important role for the genetic diversity found in this wine-growing region, suggesting the likely kinship relation between these cultivars (Castro et al., 2012; Ferreira et al., 2015).

Regarding the berry skin color feature of cv. 'Vinhão', both MYBA1 and MYBA2 loci were molecularly characterized through their allelic variations. MYBA1 locus was characterized by two different approaches: i) the detection of the non-functional allele (VvmybA1a), carried out through the presence of Gret1 retrotransposon insertion and ii) the assessment of putative functional alleles, namely the wild-type allele without any kind of insertion, VvmybA1c, or other functional alleles. 'Vinhão' genotype showed to carry only one MYBA1 allele, being homozygous for the wild-type allele, $V v m y b A 1 c$, which is characterized by no insertion in the promotor region (Fig. 1c). The fragment with $\approx 1080 \mathrm{bp}$ corresponding to VvmybA1c (MYBA1 promotor region and part of the coding sequence) was sequenced and compared with those sequences obtained from the reference grapevine genome Pinot noirderived line and no deviation was found from the reference sequence. Additionally, MYBA2 gene polymorphisms were assessed by the SNaPshot system, using VvMYBA2R44 (K980) as marker, which revealed the presence of the wild-type allele as the unique allele $(\mathrm{G} / \mathrm{G})$, called VvmybA2r, allowing the perfect function of MYBA2 gene (Fig. 1c).

In Vitis vinifera cultivars, the mutational pattern for these two color genes gives rise to different genotypic combinations that consist mainly on three haplotypes, Hap C-N, Hap C-Rs and Hap-B (Fournier-Level et al., 2010). Hap C-N is considered the ancestral haplotype, consisting of the functional genes MYBA that carries no Gret1 insertion at MYBA1 and a functional G allele at MYBA2. Hap C-Rs haplotype contains both a functional component at MYBA1 and a non-functional $\mathrm{T}$ allele on MYBA2 and Hap-B contains two non-functional alleles for both genes. Taking into account these main haplotypes of the berry color locus, cv. 'Vinhão' carries two functional alleles on both MYBA genes, i.e. the ancestral haplotype Hap C-N (Fig. 1c). Several studies suggest that the number of functional alleles affects the capability of anthocyanin accumulation in grape berry skin (Azuma et al., 2011; Carrasco et al., 2015; De Lorenzis et al., 2015; Fournier-Level et al., 2010). This could be one of the reasons whereby cv. 'Vinhão' has the capability to accumulate higher anthocyanin amounts in berry skin, with values ranging from 7274 to $11,842 \mathrm{mg} / \mathrm{kg}$ at full maturation, as previously described by Dopico-García et al. (2008), corresponding to the cultivar with the highest content of anthocyanins among the 10 different cultivars from Vinhos Verdes DOC region analyzed. Moreover, Fournier-Level et al. (2010) and Carrasco et al. (2015) also concluded that the most ancestral haplotype C-N was found in other varieties from the Iberian Peninsula, suggesting that Portuguese and Spanish grapes have kept the ancestral haplotype, which could outcome from an isolation event affecting these varieties in a region considered a glaciation refuge zone, involving limited gene flow from the east or due to their hybridization with non-domesticated endemic Vitis vinifera subsp. sylvestris.

Since the regulation of biosynthetic anthocyanin pathway in $\mathrm{V}$. vinifera is coordinated by transcriptional and post-transcriptional control of several structural genes, it is reasonable to speculate that the capacity of anthocyanin accumulation in cv. 'Vinhão' is not only due to the $M Y B$ genes allelic structure and composition at the berry color locus. In order to better understand the berry color trait of the cv. 'Vinhão', the expression patterns of structural genes involved in the biosynthesis of anthocyanins and transcription factors related with this pathway were examined at different developmental stages by using qRT-PCR method (Fig. 2). Anthocyanins' biosynthetic pathway shares the first steps of the general phenylpropanoid pathway. Thus, it is important to analyze the expression levels of genes involved in different steps along the entire pathway, including earlier genes, which can affect down-stream branches, such as the anthocyanins' pathway. During the berry development, metabolism changes are typically fast, which affects flowering and berry ripening rates, even in the same plant. Therefore, in this kind of gene expression studies is more important to consider the trends of gene expression than focused on differences in exact values at a single 
a)

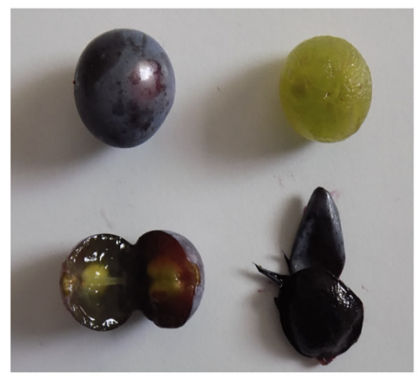

b)

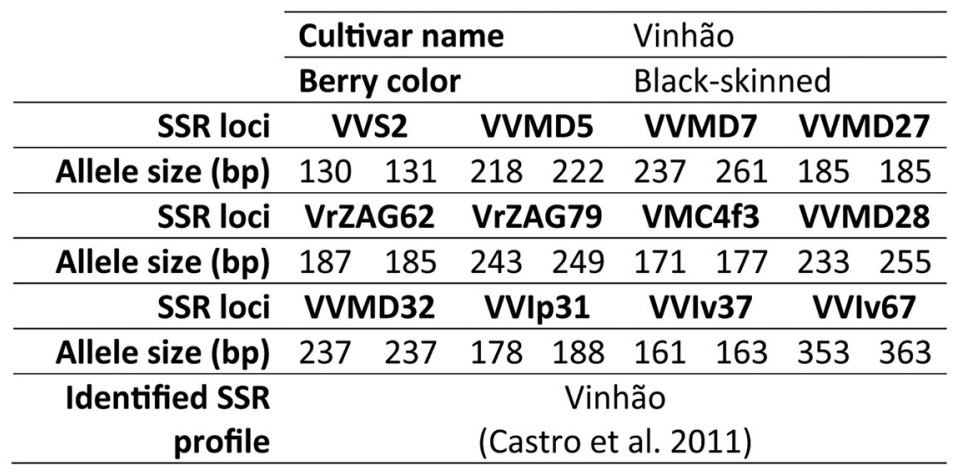

c)

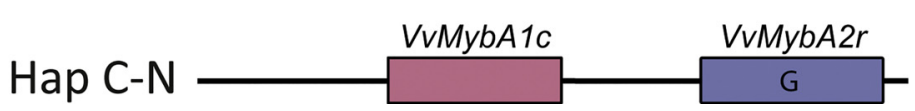

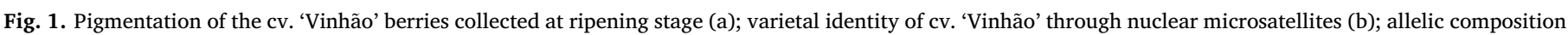
of MYBA1 and MYBA2, with the corresponding haplotype (c).

time point (Primetta et al., 2015).

After the first common steps of the phenylpropanoid pathway, the flavonoid biosynthesis is initiated by chalcone synthase (CHS) activity. CHS1 is described as the best characterized chalcone isoform in grapevine; however its expression is not constant during the growing cycle (Conde et al., 2016). The obtained data shows different expression patterns of CHS1 and CHS3 genes. CHS1 showed a significant increase between the last two stages (ripening and full maturation), with the highest expression level observed at the full maturation stage. While, CHS3 had the highest expression level at ripening stage (Fig. 2), similar to the expression pattern observed in cv. 'Corvina' by De Lorenzis et al. (2016), which showed the highest steady-state transcript abundance also at the ripening stage. Genes involved in the hydroxylation of dihydrokaempferol via flavonoid- $3^{\prime}, 5^{\prime}$ hydroxylase $\left(F 3^{\prime} 5^{\prime} H 1 a\right.$ and $F 3^{\prime} 5^{\prime} H j$ transcripts) that leads to the anthocyanin percursor delphinidin, significantly increase as the berry develops from veraison to the last stage of maturation in cv. 'Vinhão'. Despite both transcripts showed the same expression trend, as it was also observed in cv. 'Alicante Bouschet' by Falginella et al. (2012), $F 3^{\prime} 5^{\prime} H j$ is more expressed than $F 3^{\prime} 5^{\prime} H 1 a$ (Fig. 2). The parallel biosynthetic pathway that uses the same precursor, dihydroxylkaempferol to another anthocyanin precursor (cyanidin) via the enzyme flavonoid $3^{\prime}$ hydroxylase $\left(F 3^{\prime} H 1 a\right.$ transcript) only showed an increase expression at ripening stage, however with a significantly lower expression than the transcripts of the other branch of the pathway $\left(F 3^{\prime} 5^{\prime} H 1 a\right.$ and $F 3^{\prime} 5^{\prime} H j$ ) (Fig. 2). It was demonstrated that the ratio between anthocyanins trisubstituted (delphinidin, petunidin and malvidin) and disubstituted (cyanidin and peonidin) in the lateral B ring is associated with $F 3^{\prime} 5^{\prime} H / F 3^{\prime} H$ transcription level, thus affecting the anthocyanin profile (Muñoz et al., 2014). Previously, Dopico-García et al. (2008) showed that delphinidin-3-O-glucoside and malvidin-3-Oglucoside were the major anthocyanins accumulated in cv. 'Vinhão', which could be correlated with the fact that $F 3^{\prime} 5^{\prime} H s$ transcripts showed a higher transcription level than the $F 3^{\prime} H 1 a$ transcript in this cultivar. Flavonol synthase (FLS) is the first enzyme of the flavonol biosynthetic branch of the flavonoid pathway that is responsible for the conversion of dihydroflavonols to flavonols, which are important co-pigments that stabilize anthocyanins in wine. Gene expression analysis by qRT-PCR revealed that FLS4 transcript levels decreased until ripening stage and then abruptly increased, being mostly expressed at the full mature stage, probably induced by the UV-radiation (Fig. 2). The dihydroflavonol reductase enzyme (DFR) is responsible for the first committed step in the pathway leading to the synthesis of flavan-3-ols. DFR showed an increase transcription level between the green and ripening stages and the transcript abundance of the gene was slightly reduced at full mature stage. The same expression patter was observed for leucoanthocyanidin dioxygenase $(L D O X)$, however at a much higher level than DFR (Fig. 2). The expression of anthocyanidin reductase (ANR) and leucoanthocyanidin redutase (LAR1 and LAR2), which are the key enzymes of the proanthocyanidin biosynthesis showed opposite behaviors; ANR expression level increased from the green stage until full maturation and the expression level of LAR1 and LAR2 decrease during berry maturation (Fig. 2). The enzyme UDP-glucose:flavonol 3-O-glucosyl transferase (UFGT) represents the key point of anthocyanin biosynthesis pathway and catalyzes the final step of the pathway. 'Vinhão' starts to express UFGT at veraison, reaching the highest value at ripening stage and then decreased at the last sampling date (Fig. 2). Comparing cv. 'Vinhão' with the teinturier cv. 'Alicante Bouschet' analysed by Falginella et al. (2012), despite both cultivars showed a quite similar UFGT expression pattern, in cv. 'Alicante Bouschet' berry skin, the expression of this gene does not decrease at the end of maturation. The Portuguese cultivar 'Trincadeira' has been also reported as showing an increase transcript abundance of UFGT on veraison and ripening stages (Fortes et al., 2011).

Regarding the transcriptional regulation of the pathway during berry development, some $M Y B$ factors, such as $M Y B 4 b$, possess repressor activities and inhibit phenolic compound synthesis. This gene has been described as a direct repressor of anthocyanin synthesis once it negatively regulates the UFGT gene expression (Matus et al., 2009). Thus, it was expected that $M Y B 4 b$ showed an inverse expression profile to that observed for UFGT gene, showing the highest level of expression at green stage and then decreasing, reaching the lowest values at the last two sampling dates, corresponding to ripening and full maturation stages (Fig. 2). Furthermore, the expression pattern of MYBA1 and $M Y B A 2$, which are the two direct regulatory genes of UFGT expression revealed to follow the same trend, with a peak of expression at veraison, overlapping, as expected, with the expression profile of UFGT (Fig. 2). Contrary to MYBA1 and MYBA2 genes that specifically control the last biosynthetic step of anthocyanin synthesis, MYB5a and MYB5b appear to regulate earlier steps and other sub-branches of the phenylpropanoid pathway, namely the synthesis of flavan-3-ols (Ali et al., 2011). The transcript profiles of $M Y B 5 a$ and $M Y B 5 b$ were similar during berry development on cv. 'Vinhão', being mainly expressed before veraison, reaching the highest transcription level at green stage (Fig. 2), which showed a coordinated expression with its target genes LAR1/LAR2.

$O$-methyltransferases (OMT) catalyze the conversion of cyanidin-3$O$-monoglucoside into peonidin-3-O-monoglucoside and delphinidin-3$O$-monoglucoside into petunidin- and malvidin-3-O-monoglucoside and it has been suggested that the expression of OMT genes is correlated 

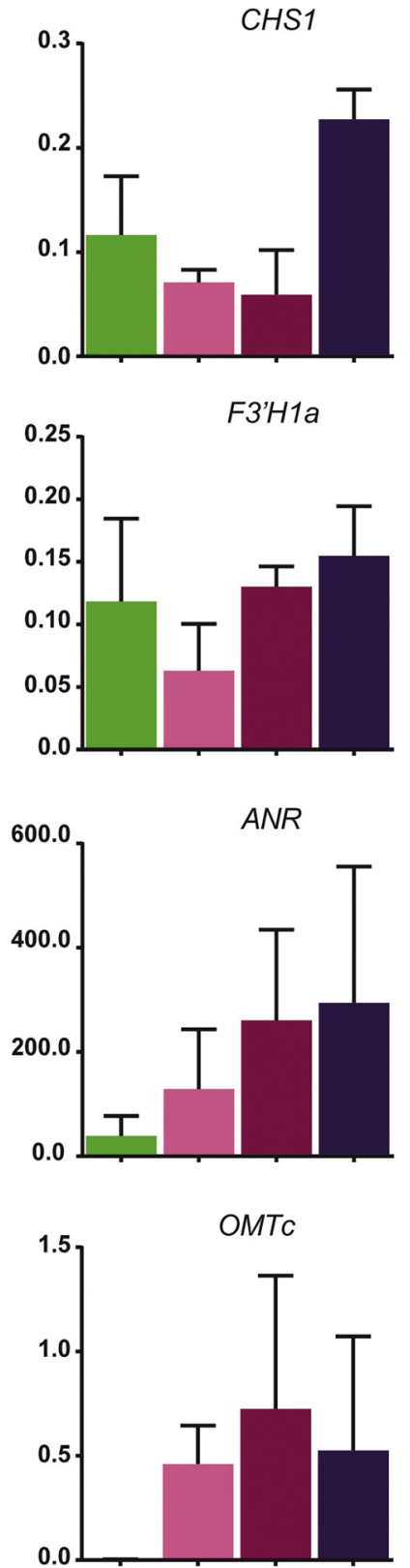
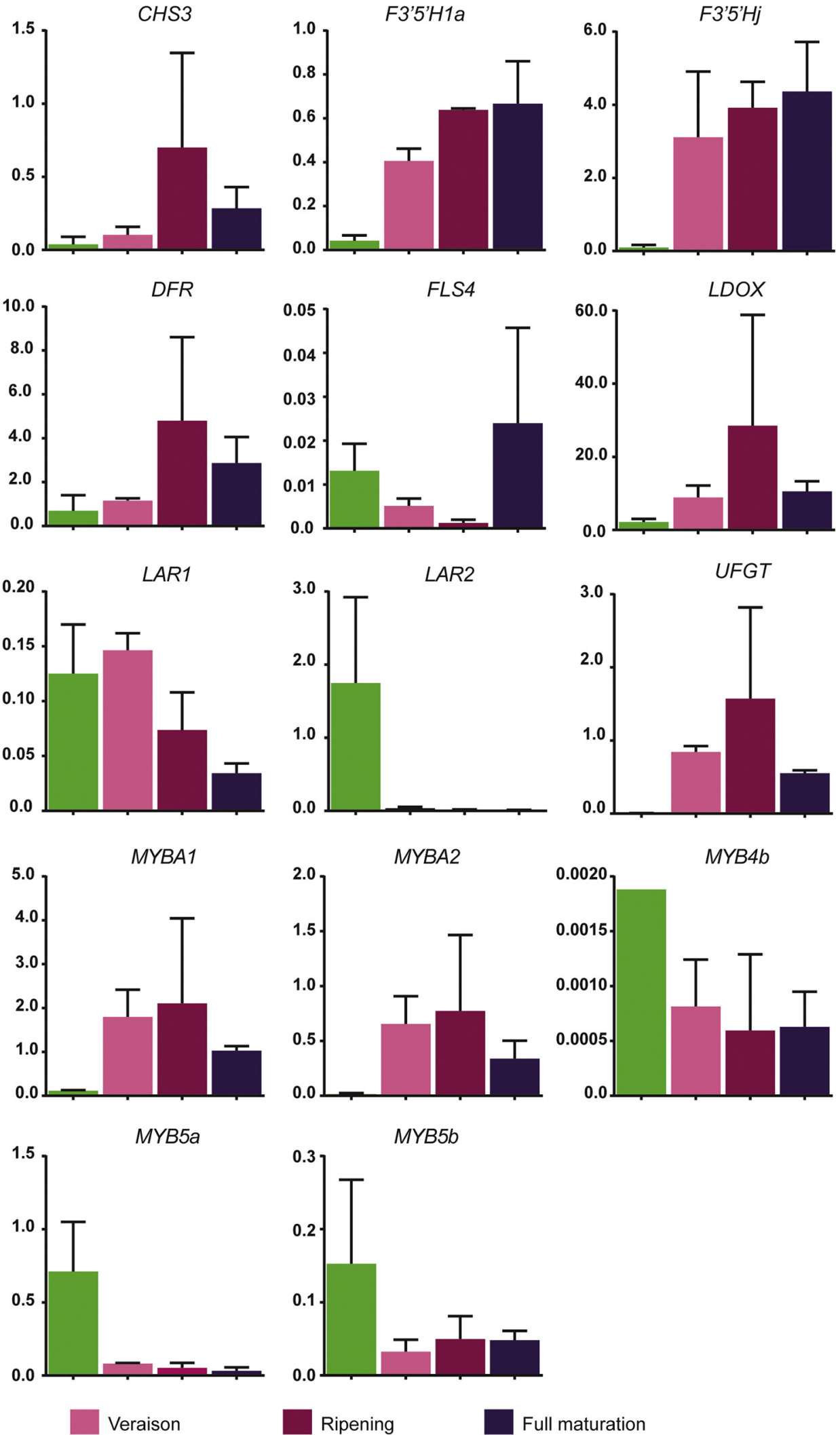

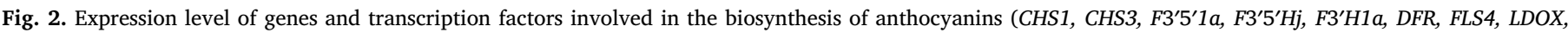

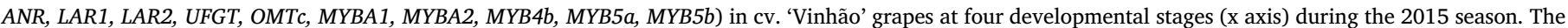

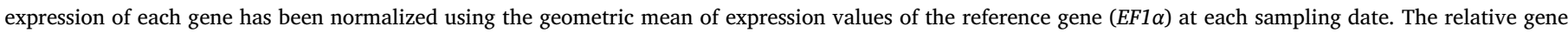
expression (y axis) has been determined based on the $2^{-\Delta \mathrm{Ct}}$ method. Error bars represent the standard deviation. 
with the accumulation of methylated anthocyanins in grapevine, which may affect color stability (Ageorges et al., 2006; Hugueney et al., 2009). The results obtained for the cv. 'Vinhão' showed that OMTc is steadily induced at veraison, which corresponds to the stage where anthocyanins start to be accumulated in pigmented cultivars, with an even higher transcript level at ripening stage, and then slightly decline towards full mature stage (Fig. 2). This expression profile matches with the transcriptional levels of OMT genes on other pigmented cultivars, such as cv. 'Cabernet Sauvignon', cv. 'Norton' (Ali et al., 2011) and cv. 'Alicante Bouschet' (Falginella et al., 2012).

\section{Conclusions}

In this study, a molecular characterization focused on the genetics behind the high pigmented berries of the cv. 'Vinhão' was performed for the first time, by the analysis of MYBA1 and MYBA2 allelic composition and also by the analysis of the expression patterns of genes involved in the anthocyanin biosynthetic pathway during berry development. The findings obtained helped to clarify the genetics underlying the intense berries skin pigmentation that characterizes this autochthonous Portuguese cultivar, suggesting that $M Y B A$ genes play a major role on the berry skin color of the cv. 'Vinhão'. This highly pigmented cultivar revealed to be homozygous for functional alelles on both MYBA genes, corresponding to the most ancestral haplotype (Hap C-N). This study focused on berry skin color of this cultivar is of major importance for breeding programs that could contribute to improving cv. 'Vinhão' grape quality and attract more attention to this Portuguese cultivar, being expected that it will be used to produce even more high quality red wines in the future.

\section{Acknowledgments}

This work was supported by European Investment Funds through FEDER/COMPETE/ POCI - Operational Competitiveness and Internationalization Programme, under Project POCI-01-0145-FEDER006958, and National Funds by FCT - Portuguese Foundation for Science and Technology, under the project UID/AGR/04033/2013. V. Ferreira is also indebted to FCT for her grant (SFRH/BD/96400/2013). Work in R. Arroyo-García lab is funded by the Project Grants RTA201400029-C03-01. The authors would like to thank Estação Vitivinícola Amândio Galhano (EVAG) for kindly allowing the sampling of plant material.

\section{References}

Ageorges, A., Fernandez, L., Vialet, S., Merdinoglu, D., Terrier, N., Romieu, C., 2006. Four specific isogenes of the anthocyanin metabolic pathway are systematically co-expressed with the red colour of grape berries. Plant Sci. 170, 372-383. https://doi.org/ 10.1016/j.plantsci.2005.09.007.

Ali, M.B., Howard, S., Chen, S., Wang, Y., Yu, O., Kovacs, L.G., Qiu, W., 2011. Berry skin development in Norton grape: distinct patterns of transcriptional regulation and flavonoid biosynthesis. BMC Plant Biol. 11, 7. https://doi.org/10.1186/1471-2229 11-7.

Azuma, A., Kobayashi, S., Yakushui, H., Yamada, M., Mitani, N., Sato, A., 2007. VvmybA1 genotype determines grape skin color. Vitis 46, 154-155.

Azuma, A., Kobayashi, S., Mitani, N., Shiraishi, M., Yamada, M., Ueno, T., Kono, A., Yakushiji, H., Koshita, Y., 2008. Genomic and genetic analysis of Myb -related genes that regulate anthocyanin biosynthesis in grape berry skin. Theor. Appl. Genet. 117, 1009-1019. https://doi.org/10.1007/s00122-008-0840-1.

Azuma, A., Udo, Y., Sato, A., Mitani, N., Kono, A., Ban, Y., Yakushiji, H., Koshita, Y., Kobayashi, S., 2011. Haplotype composition at the color locus is a major genetic determinant of skin color variation in Vitis $\times$ labruscana grapes. Theor. Appl. Genet. 122, 1427-1438. https://doi.org/10.1007/s00122-011-1542-7.

Carrasco, D., De Lorenzis, G., Maghradze, D., Revilla, E., Bellido, A., Failla, O., ArroyoGarcía, R., 2015. Allelic variation in the VvMYBA1 and VvMYBA2 domestication genes in natural grapevine populations (Vitis vinifera subsp. sylvestris). Plant Syst. Evol. 301, 1613-1624. https://doi.org/10.1007/s00606-014-1181-y.

Castro, I., Martín, J.P., Ortiz, J.M., Pinto-Carnide, O., 2011. Varietal discrimination and genetic relationships of Vitis vinifera L. cultivars from two major controlled appellation (DOC) regions in Portugal. Sci. Hortic. 127, 507-514. https://doi.org/10.1016/j. scienta. 2010.11.018.

Castro, I., Martín, J.P., Ortiz, J.M., Mota, M.T., Pinto-Carnide, O., Martin, J., Ortiz, J.M., Mota, M.T., Pinto-Carnide, O., 2012. The Portuguese grapevine cultivar 'Amaral': synonymies, homonymies and misnames. Vitis 51, 61-63.

Conde, A., Pimentel, D., Neves, A., Dinis, L.-T., Bernardo, S., Correia, C.M., Gerós, H., Moutinho-Pereira, J., 2016. Kaolin foliar application has a stimulatory effect on phenylpropanoid and flavonoid pathways in grape berries. Front. Plant Sci. 7, 1-14. https://doi.org/10.3389/fpls.2016.01150.

De Lorenzis, G., Carrasco, D., Arroyo-García, R., Rossoni, M., Di Lorenzo, G.S., Failla, O. 2015. Investigation of $V v M y b A 1$ and $V v M y b A 2$ berry color genes in 'Aglianico' biotypes. Vitis 54, 43-44.

De Lorenzis, G., Rustioni, L., Parisi, S.G., Zoli, F., Brancadoro, L., 2016. Anthocyanin biosynthesis during berry development in corvina grape. Sci. Hortic. 212, 74-80. https://doi.org/10.1016/j.scienta.2016.09.039.

Dopico-García, M.S., Fique, A., Guerra, L., Afonso, J.M., Pereira, O., Valentão, P., Andrade, P.B., Seabra, R.M., 2008. Principal components of phenolics to characterize red Vinho Verde grapes: anthocyanins or non-coloured compounds? Talanta 75, 1190-1202. https://doi.org/10.1016/j.talanta.2008.01.012.

Falginella, L., Di Gaspero, G., Castellarin, S.D., 2012. Expression of flavonoid genes in the red grape berry of "Alicante Bouschet" varies with the histological distribution of anthocyanins and their chemical composition. Planta 236, 1037-1051. https://doi. org/10.1007/s00425-012-1658-2.

Ferreira, V., Pinto-Carnide, O., Mota, T., Martín, J.P., Ortiz, J.M., Castro, I., 2015 Identification of minority grapevine cultivars from Vinhos Verdes Portuguese DOC Region. Vitis 54, 53-58.

Ferreira, V., Castro, I., Carrasco, D., Pinto-Carnide, O., Arroyo-García, R., 2018. Molecular characterization of berry skin color reversion on grape somatic variants. J. Berry Res. 8, 147-162. https://doi.org/10.3233/JBR-170289.

Fonseca, F.P.R., 1791. Memória sobre o estado da Agricultura, e Commercio do Alto Douro. Memórias Económicas Da Academia Real Das Ciências de Lisboa, Tomo III. Academia Real das Ciências de Lisboa, Lisboa, Portugal, pp. 73-153.

Fortes, A.M., Agudelo-Romero, P., Silva, M.S., Ali, K., Sousa, L., Maltese, F., Choi, Y.H., Grimplet, J., Martinez-Zapater, J.M., Verpoorte, R., Pais, M.S., 2011. Transcript and metabolite analysis in Trincadeira cultivar reveals novel information regarding the dynamics of grape ripening. BMC Plant Biol. 11, 149. https://doi.org/10.1186/14712229-11-149.

Fournier-Level, A., Lacombe, T., Le Cunff, L., Boursiquot, J.-M.M., This, P., 2010. Evolution of the $V v M y b A$ gene family, the major determinant of berry colour in cultivated grapevine (Vitis vinifera L.). Heredity (Edinb.) 104, 351-362. https://doi. org/10.1038/hdy.2009.148.

Hugueney, P., Provenzano, S., Verries, C., Ferrandino, A., Meudec, E., Batelli, G., Merdinoglu, D., Cheynier, V., Schubert, A., Ageorges, A., 2009. A novel cation-dependent $O$-methyltransferase involved in anthocyanin methylation in grapevine. Plant Physiol. 150, 2057-2070. https://doi.org/10.1104/pp.109.140376.

Kobayashi, S., Goto-Yamamoto, N., Hirochika, H., 2004. Retrotransposon-induced mutations in grape skin color. Science 304https://doi.org/10.1126/science.1095011. 982-982.

Lijavetzky, D., Ruiz-García, L., Cabezas, Ja, De Andrés, M.T., Bravo, G., Ibáñez, A., Carreño, J., Cabello, F., Ibáñez, J., Martínez-Zapater, J.M., 2006. Molecular genetics of berry colour variation in table grape. Mol. Genet. Genomics 276, 427-435. https:// doi.org/10.1007/s00438-006-0149-1.

Martín, J.P., Santiago, J.L., Pinto-Carnide, O., Leal, F., Martinez, M.D., Ortiz, J.M., 2006. Determination of relationships among autochthonous grapevine varieties (Vitis vinifera L.) in the northwest of the Iberian peninsula by using microsatellite markers. Genet. Resour. Crop Evol. 53, 1255-1261. https://doi.org/10.1007/s10722-0055679-6.

Matus, J.T., Loyola, R., Vega, A., Peña-Neira, A., Bordeu, E., Arce-Johnson, P., Alcalde, J.A., 2009. Post-veraison sunlight exposure induces MYB-mediated transcriptional regulation of anthocyanin and flavonol synthesis in berry skins of Vitis vinifera. J. Exp. Bot. 60, 853-867. https://doi.org/10.1093/jxb/ern336.

Migliaro, D., Crespan, M., Muñoz-Organero, G., Velasco, R., Moser, C., Vezzulli, S., 2017. Structural dynamics at the berry colour locus in Vitis vinifera L. somatic variants. Acta Hortic. 1157, 27-32. https://doi.org/10.17660/ActaHortic.2017.1157.5.

Muñoz, C., Gomez-Talquenca, S., Chialva, C., Ibáñez, J., Martinez-Zapater, J.M.J.M., Peña-Neira, Á., Lijavetzky, D., 2014. Relationships among gene expression and anthocyanin composition of Malbec grapevine clones. J. Agric. Food Chem. 62, 6716-6725. https://doi.org/10.1021/jf501575m.

OIV, 2009. 2nde Édition de la Liste des Descripteurs OIV pour les Variétés et Espèces de Vitis, 2nd ed. OIV, Paris France.

Primetta, A.K., Karppinen, K., Riihinen, K.R., Jaakola, L., 2015. Metabolic and molecular analyses of white mutant Vaccinium berries show down-regulation of MYBPA1-type R2R3 MYB regulatory factor. Planta 242, 631-643. https://doi.org/10.1007/s00425015-2363-8.

Reid, K.E., Olsson, N., Schlosser, J., Peng, F., Lund, S.T., 2006. An optimized grapevine RNA isolation procedure and statistical determination of reference genes for real-time RT-PCR during berry development. BMC Plant Biol. 6, 27. https://doi.org/10.1186/ 1471-2229-6-27.

Teixeira, N., Azevedo, J., Mateus, N., de Freitas, V., 2016. Proanthocyanidin screening by LC-ESI-MS of Portuguese red wines made with teinturier grapes. Food Chem. 190, 300-307. https://doi.org/10.1016/j.foodchem.2015.05.065.

This, P., Lacombe, T., Cadle-Davidson, M., Owens, C.L., 2007. Wine grape (Vitis vinifera L.) color associates with allelic variation in the domestication gene VvmybA1. Theor. Appl. Genet. 114, 723-730. https://doi.org/10.1007/s00122-006-0472-2.

Vezzulli, S., Leonardelli, L., Malossini, U., Stefanini, M., Velasco, R., Moser, C., 2012. Pinot blanc and Pinot gris arose as independent somatic mutations of Pinot noir. J. Exp. Bot. 63, 6359-6369. https://doi.org/10.1093/jxb/ers290.

Walker, A.R., Lee, E., Bogs, J., McDavid, D.A.J., Thomas, M.R., Robinson, S.P., 2007. White grapes arose through the mutation of two similar and adjacent regulatory genes. Plant J. 49, 772-785. https://doi.org/10.1111/j.1365-313X.2006.02997.x.

Yakushiji, H., Kobayashi, S., Goto-Yamamoto, N., Tae Jeong, S., Sueta, T., Mitani, N., Azuma, A., 2006. A skin color mutation of grapevine, from black-skinned Pinot noir to white-skinned Pinot blanc, is caused by deletion of the functional VvmybA1 allele. Biosci. Biotechnol. Biochem. 70, 1506-1508. https://doi.org/10.1271/bbb.50647. 